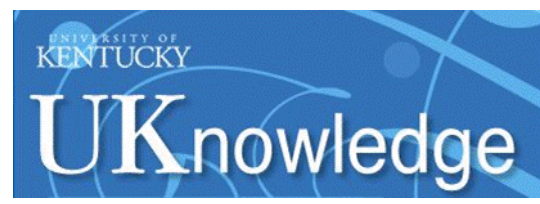

University of Kentucky

UKnowledge

1988

\title{
Non-local Spirantization in Breton
}

\author{
Gregory Stump \\ University of Kentucky, gstump@uky.edu
}

Follow this and additional works at: https://uknowledge.uky.edu/lin_facpub

Part of the Linguistics Commons

Right click to open a feedback form in a new tab to let us know how this document benefits you.

\section{Repository Citation}

Stump, Gregory, "Non-local Spirantization in Breton" (1988). Linguistics Faculty Publications. 27. https://uknowledge.uky.edu/lin_facpub/27

This Article is brought to you for free and open access by the Linguistics at UKnowledge. It has been accepted for inclusion in Linguistics Faculty Publications by an authorized administrator of UKnowledge. For more information, please contact UKnowledge@lsv.uky.edu. 


\section{Non-local Spirantization in Breton}

Digital Object Identifier (DOI)

10.1017/S0022226700011865 


\title{
Non-local spirantization in Breton ${ }^{1}$
}

\author{
GREGORY T. STUMP \\ University of Kentucky
}

(Received I January I988; revised 22 March I988)

\section{INTRODUCTION}

Among the most striking morphosyntactic characteristics shared by the Celtic languages are their elaborate consonant mutation systems. It is clear from the most cursory inspection that in such systems, the range of possible syntactic relations between mutation triggers and their targets is subject to principled limits. In a recent paper, Zwicky (1984) has hypothesized that trigger-target relations are universally restricted by the constraint in (I):

(I) The trigger determining a rule feature for a morphophonemic rule must be adjacent to the affected word and c-command it (Zwicky, I $984: 389$ ).

Following Zwicky, I shall refer to this as the TRIGGER CONSTRAINT. The effect of this constraint is to rule out the possibility that a word may undergo a particular morphophonemic rule as the result of the influence of some 'nonlocal' triggering expression. As Zwicky shows, certain evidence from the Welsh system of initial consonant mutations appears to require the postulation of non-local mutation triggers, and thus seems to disconfirm the Trigger Constraint. He argues convincingly, however, that the Welsh evidence can in fact be brought into conformity with this constraint. Here, I will present some data from the Breton mutation system which poses genuine difficulties for the Trigger Constraint; depending upon one's assumptions, the reconciliation of this data with the version of the Trigger Constraint in ( $\mathrm{I}$ ) is either impossible, or can only be achieved through the introduction of an unprecedented sort of rule.

My discussion will proceed as follows. In Section 2, the Breton system of consonant mutations is briefly sketched, and a class of apparently non-local mutations in this system is identified. Section 3 is a summary of the

[I] Different versions of this paper were presented at the 39th Kentucky Foreign Language Conference (April 1986) and at a Chicago Linguistic Society monthly meeting (May 1986); I would like to thank the audiences at both gatherings for a number of helpful comments. Particular thanks go to Steve Harlow, Jim McCloskey, and Jerry Sadock; also to Reun Ar C'halan and Gwennole Le Menn for their invaluable help as speakers and scholars of Breton. Needless to say, these people do not all necessarily agree with the conclusions drawn here. 
superficially similar cases of apparently non-local mutations in Welsh, and of the alternative approaches which Zwicky proposes in order to bring them into conformity with the Trigger Constraint. In Section 4, Zwicky's proposals are shown to provide unsatisfactory solutions to the problems posed by the Breton data; in Section 5, two additional means of reconciling the Breton data with the Trigger Constraint are likewise considered and rejected. In Section 6, the conclusions and implications of Sections 2-5 are summarized; it is suggested that the Trigger Constraint, as it is stated in (1), merely embodies the unmarked option for expressions which trigger morphophonemic rules, and that some truly radical solution is required to account for morphophonemic systems in which non-local mutations appear as a marked option. In Section 7, two such solutions are considered: in the first of these, a revised, weakened version of the Trigger Constraint is proposed which permits the intervention of a named element between a mutation trigger and its target; the second solution, on the other hand, allows the Trigger Constraint to be maintained in its original, stronger form, but entails the existence of rules which may locally transmit mutation-triggering properties from one word to another. In the concluding Section 8 , the differences between these two approaches are briefly discussed; neither approach, however, is exclusively advocated.

\section{AN APPARENT CASE OF NON-LOCAL MUTATION IN BRETON}

Like the other Celtic languages, Breton possesses an elaborate system of grammatically conditioned word-initial consonant mutations. Although this system is complicated by sporadic irregularities, four fundamental varieties of mutation can be observed in Breton : these are the leniting, the reinforcing, the spirantizing, and the mixed mutations, whose effects are indicated in Table $1 .^{2}$

For instance, the possessive determiners $d a$ 'thy' and $e$ 'his' cause a following noun to undergo lenition, as in (2); the determiner ho 'your (pl.)',

[2] Throughout, examples are presented in conventional Breton orthography. The following two details regarding this system of orthography should be taken into account:

(i) As the alternant of $g$ under lenition and the mixed mutation, $c h$ represents a voiced glottal fricative.

(ii) Word-initial voiceless fricatives are sometimes voiced when preceded by a resonant (Jackson (1967: 360-375), Willis ( $1982: 24 \mathrm{f}$., $114 \mathrm{ff}$.)); thus, since all spirantization triggers end with resonants, the spirant alternants of the voiceless stops are frequently voiced indeed, in the standard orthography, the spirant alternant of $t$ is explicitly represented as voiced, as in Table 1 . As for the spirant alternants of $p$ and $k$, they may be voiced or voiceless, depending on the dialect; note, in particular, that the $c^{\prime} h$ in Table I may be phonetically realized as $[\mathrm{x}]$ or as $[\mathrm{h}]$.

See Jackson (1967) for a very detailed account of other minor differences which the various dialects of Breton show in their systems of initial consonant mutation. 


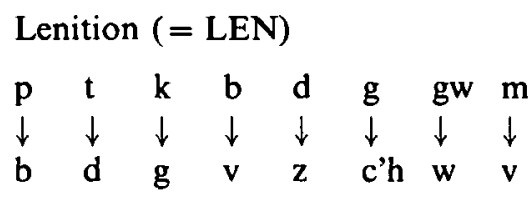

\begin{tabular}{lll}
\multicolumn{3}{l}{ Reinforcem } \\
b & d & g \\
$\downarrow$ & $\downarrow$ & $\downarrow$ \\
p & t & k
\end{tabular}

\begin{tabular}{lll}
\multicolumn{3}{l}{ Spirantization } \\
$\mathbf{p}$ & $\mathbf{t}$ & $\mathbf{k}$ \\
$\downarrow$ & $\downarrow$ & $\downarrow$ \\
$\mathbf{f}$ & $\mathbf{z}$ & $\mathrm{c}$ \\
\end{tabular}

Mixed mutation

$\begin{array}{lllll}\mathrm{b} & \mathrm{d} & \mathrm{g} & \mathrm{gw} & \mathrm{m} \\ \downarrow & \downarrow & \downarrow & \downarrow & \downarrow \\ \mathrm{v} & \mathrm{t} & \mathrm{c} h & \mathrm{w} & \mathrm{v}\end{array}$

Table I

Breton mutations

on the other hand, triggers the reinforcement mutation, as in (3); and $v a$ 'my', he 'her', and $o$ 'their' trigger the spirantization mutation, as in (4).

(2) (a) tad

(b) mamm

'father'

'mother'

(3) breur

(4) (a) penn

(b) tal

(c) $\mathrm{ki}$ 'brother'

'head'

'forehead'

'dog' da dad 'thy father'

e vamm 'his mother'

ho preur 'your brother'

va fenn 'my head'

he zal 'her forehead'

o c'hi 'their dog'

Certain triggers operate conditionally, producing a mutation only if the target expression belongs to a specific category; for instance, the definite and indefinite articles produce a lenition just in case the target expression is a feminine singular noun or a masculine plural noun referring to humans. Thus, in (5), the feminine noun bag 'boat' is lenited in the singular but not the plural, while the masculine noun paotr 'boy' is lenited in the plural rather than the singular.

(5) (a) ar vag 'the boat'

(b) ar paotr 'the boy' ar bagoù 'the boats'

ar baotred 'the boys' 
When an article is immediately followed by a masculine singular noun or by any plural noun other than one which is both masculine and human in reference, the article does not trigger any sort of mutation in the noununless the noun begins with $k$. In this one case, both the definite and indefinite articles spirantize the $k$, as in (6b) and $(7 \mathrm{c})$.

(6) (a) kemener

(b) ar c'hemener

(c) ar gemenerien

(7) (a) kemenerez

(b) ar gemenerez

(c) ar c'hemenerezed 'tailor (masc.)'

'the tailor'

'the tailors'

'seamstress (fem.)'

'the seamstress'

'the seamstresses'

The first person plural possessive determiner hor 'our' produces this same defective spirantization of $k$, as in (8), but otherwise produces no mutation : ${ }^{3}$

(8) (a) hor c'hemener

'our tailor'

(b) hor c'hemenerien

'our tailors'

(c) hor c'hemenerez

'our seamstress'

(d) hor c'hemenerezed

'our seamstresses'

A class of apparent counterexamples to the Trigger Constraint appears among noun phrases containing prenominal adjectives. As is usual for VSO languages, Breton ordinarily requires adjectives to follow the nouns they modify. Nevertheless, certain kinds of adjectives may precede. Among these are: (i) numeral adjectives, whether cardinal or ordinal; (ii) comparative and superlative adjectives; and (iii) a small number of adjectives in the positive degree, including berr 'short', brizh 'spotted, motley (pejorative)', dister 'puny', gwall 'bad', gwir 'true', hir 'long', holl 'all, whole', kaezh 'poor', $k o z h$ 'old (pejorative)', and $k r a k$ 'short'. With the exception of a handful of cardinal numerals and a few of the adjectives in (iii), prenominal adjectives of the sorts listed in (i)-(iii) do not trigger any kind of mutation in the noun they modify.

Of central importance here is the quantifying adjective holl 'all/whole'. ${ }^{4}$ In prenominal position, holl ordinarily triggers a lenition in an immediately following noun, as in $(9) .^{5}$

[3] In nonstandard dialects of Trégorrois, however, the first person plural possessive determiner hom/hon 'our' triggers the full range of spirantizations given in Table I (Trépos, n.d.[1968]: 46; Kervella, 1947: 95).

The articles $a r, u r$ and the possessive determiner hor each show three alternants, whose choice depends on the initial segment of the following word : al, ul, hol appear before $l$; an, $u n$, hon appear before dental stops, vowels, and $h$; and $a r, u r$, hor are used elsewhere.

[4] Holl is sometimes spelled as oll. Le Clerc (1911: 60, fn2) notes that some writers use the spelling holl for adjectival functions and the spelling oll for adverbial functions.

[5] Le Gléau (1973: 52) observes that in the works of some Breton writers, holl does not produce any sort of mutation, but this is apparently the exception rather than the rule. 
(9) (a) holl zeizioù va buhez 'all the days of my life' (holl lenites deizioù 'days')

(b) hon holl c'hed 'all our hope' (holl lenites ged 'hope')

(c) an holl di 'the whole house' (holl lenites $t i$ 'house')

In some instances, however, prenominal holl apparently allows a preceding determiner to effect a mutation in the head noun, as though holl were itself 'invisible' as an element intervening between a mutation trigger and its target. The precise circumstances in which a determiner may trigger a mutation in a noun despite the appearance of an intervening holl vary considerably from one dialect to another. Some dialects actually seem to lack this phenomenon, ${ }^{6}$ certain others have altogether abandoned the use of holl. ${ }^{7}$ In view of these complications, I shall focus my attention on this phenomenon as it has been described by Kervella (1947) and Trépos (n.d. [1968]) (natives of northwestern and southwestern Cornouaille, respectively); in Section 6, however, I will mention five slightly different dialects, described by Moal (1890), Hingant (1868), Malmanche (1907), Le Gléau (1973), and Le Roux (1896).

According to Kervella (1947:97) and Trépos (n.d. [1968]:46), there is only one set of circumstances in which holl may intervene between a determiner and a noun without preventing the determiner from triggering a mutation in the noun, namely when the determiner is one which triggers the full range of spirantizations in Table I ( $v a$ 'my', $h e$ 'her', and $o$ 'their'). Thus, while one might expect holl to lenite the following noun in examples such as (I0)-(12), the noun has, in each case, undergone initial spirantization, apparently owing to the influence of the non-contiguous possessive determiner. ${ }^{8}$

(10) (a) va holl zud 'all my people' (spirantization of tud 'people')

(b) va holl flijadur 'all my pleasure' (spirantization of plijadur 'pleasure')

[6] The following grammars and dictionarics consulted during the preparation of this article made no explicit mention of this phenomenon: Ernault (1897), Ernault (1984), Guillevic \& Le Goff (1942), Guillome (1836), Hardie (1948), Hemon (1975a), Hemon (1978), Le Clerc (1911), Le Fèvre (1818), Le Gonidec (1838), Normant (1902), Société armoricaine du Breuriez ar Feiz (1847), Sommerfelt (1920), Ternes (1970), Treasure (1903), Troude (1842), and Vallee (1926). Nothing definite can be inferred from the fact that these grammars and dictionaries do not mention the possibility that holl may intervene between a mutation trigger and its target; certain grammarians may have simply overlooked this peculiarity of the Breton mutation system, or may have decided not to discuss it. It is clear, however, that at least some dialects lack this phenomenon altogether; see footnote 17.

[7] Gwennole Le Menn pointed this out to me. In Sommerfelt's (1920: 154) description of the dialect of Saint-Pol-de-Léon, the use of holl is classified as rare.

[8] As Kervella (1947: 97) notes, the non-local spirantization triggered by he 'her' in examples such as those in (11) serves a disambiguating function: because he and $e$ 'his' are phonetically identical, the appearance of this spirantization is the only way of distinguishing between he holl feadra 'her entire fortune' and $e$ holl beadra 'his entire fortune', etc. 
(II) (a) he holl c'harantez 'all her love' (spirantization of karantez 'love')

(b) he holl feadra 'her entire fortune' (spirantization of peadra 'fortune')

(12) (a) o holl zrubuilhoù 'all their troubles' (spirantization of trubuilhoù 'troubles')

(b) o holl fer 'all their pears' (spirantization of per 'pears')

Examples such as (I0)-(12) constitute prima facie evidence against the Trigger Constraint; in each example, an expression has been affected by a morphophonemic rule triggered by the presence of a particular non-adjacent expression.

What is especially bothersome about this phenomenon is that it does not submit at all straightforwardly to either of the alternative solutions proposed by Zwicky (1984) for the superficially analogous problem of lenited direct objects in Welsh. In the following two sections, Zwicky's solutions are briefly summarized and their inapplicability to the Breton data exemplified in (10)-(12) is demonstrated.

\section{ZWICKY'S ACCOUNTS OF LENITED DIRECT OBJECTS IN WELSH}

As noted above, Welsh presents apparent instances of non-local mutation which are superficially quite similar to the Breton examples discussed in the preceding section. In Welsh, the direct object of a finite verb is lenited; yet, finite verbs and their objects are ordinarily non-contiguous, Welsh being a VSO language. Thus, $c i$ 'dog' is lenited by gwelodd 'saw' in (13), even though the two words are separated by the subject noun phrase $y d y n$ 'the man'.

(13) Gwelodd y dyn gi. saw-3sG the man dog

'The man saw a dog.'

Despite the seemingly non-local nature of the mutation in (I3) and similar sentences, Zwicky develops two alternative analyses, either one of which is sufficient to reconcile the Trigger Constraint with such apparent counterexamples.

\subsection{Phantom VPs in Welsh}

As the basis for his first account, Zwicky presents evidence suggesting that Welsh possesses a VP constituent whose parts may be continuous (as in the infinitive construction $y n$ gweld $c i$ in (14)) or discontinuous (as in the finite construction gwelodd...gi in (13)).

(I4) Yr oedd y dyn yn gweld ci. PCL was-3SG the man in to-see dog 'The man saw a dog.' 
As he shows, there is no formal obstacle to the postulation of discontinuous constituents in monostratal theories of syntax. Within the GPSG framework, for example, the Welsh VP could be treated as a 'phantom category'. That is, VP could be expanded in a number of ways, by phrase structure rules such as those in (15):

(15) (a)

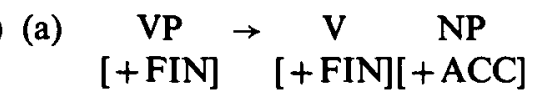

(b) $\underset{[+ \text { FIN }]}{\mathrm{VP}} \rightarrow \underset{[+\mathrm{FIN}]}{\mathrm{V}} \mathrm{PP}$

VP itself, however, would never be introduced by any phrase structure rule expanding any other category; instead, its sole function would be to allow metarules to induce new phrase structure rules for the expansion of $S$. Thus, the VP expansion rules in (I5) would allow metarule (I6) to induce the rules in (17), which would admit finite clauses such as (I3).

(I6) Finite clause metarule:

$$
\begin{array}{clll}
\mathrm{VP} & \rightarrow \underset{[+\mathrm{FIN}]}{\mathrm{V}} \ldots & \\
& \downarrow & & \\
\mathrm{S} & \rightarrow \underset{[+\mathrm{FIN}]}{\mathrm{V}} \mathrm{NP} & \ldots
\end{array}
$$

(17) (a)

$$
\text { (a) } \mathrm{S} \rightarrow \underset{[+\mathrm{FIN}]}{\mathrm{V}} \mathrm{NP} \underset{[+\mathrm{ACC}]}{\mathrm{NP}}
$$

(b) $\mathrm{S} \rightarrow \underset{[+\mathrm{FIN}]}{\mathrm{V}} \mathrm{NP} \quad \mathrm{PP}$

Under this analysis, the lenition of the direct object by the finite verb in a sentence such as (13) need not be viewed as a non-local mutation, and is thus easily reconciled with the Trigger Constraint. Although the mutation trigger $\mathrm{V}[+$ FIN $]$ is not adjacent to its target NP + ACC $]$ in the structures admitted by ( 17 a), these two categories ARE adjacent in the expansion of VP permitted by rule $(15 \mathrm{a})$, and it is this rule which licenses the induction of ( $17 \mathrm{a})$ by means of metarule (I6). Suppose, now, that V[+FIN] imposes the rule feature [+ LEN] on NP[ + ACC] as an effect of rule (15a), as in (I8). Under this assumption, the required structural relation between trigger and target is clearly fulfilled, and the Trigger Constraint can thus be maintained.

$$
\begin{aligned}
& \text { VP } \rightarrow \text { V NP } \\
& {[+ \text { FIN }] \quad\left[\begin{array}{c}
+ \text { FIN } \\
\text { LEN trigger }
\end{array}\right]\left[\begin{array}{l}
+ \text { ACC } \\
+ \text { LEN }
\end{array}\right]}
\end{aligned}
$$

Note that on this analysis, it is critical that morphophonemic rule features be distributed by the phrase structure rules themselves and not by an 
interpretive component applying to syntactic tree structures once they have been admitted as syntactically well-formed. The reason for this is clear: if an interpretive component were responsible for distributing these rule features, it would not be possible for the verb in (13) to impose the feature [+LEN] on the direct object, since the Trigger Constraint would prevent it from doing so. In other words, the Trigger Constraint must here be viewed as a restriction on the distribution of morphophonemic rule features by phrase structure rules; in particular, it must be viewed as restricting the form of BASIC phrase structure rules - that is those which do not arise through the operation of a metarule such as (16). ${ }^{9}$

\subsection{Lenition by default in Welsh}

In addition to the foregoing solution Zwicky presents a second way of reconciling the Trigger Constraint with the apparently non-local mutation in (13). According to this second approach, Welsh noun phrases are lenited by default - that is, a NP automatically undergoes initial lenition precisely when it Is NOT under the influence of a neighbouring trigger. Zwicky cites two compelling pieces of evidence favouring a default lenition analysis of Welsh noun phrases. First, he points out that while the other Welsh mutations are produced by only a handful of triggering expressions, lenition occurs in a disproportionately wide range of contexts. In addition, lenition, unlike the other mutations, frequently appears despite the absence of any adjacent, ccommanding trigger, as for example in vocatives, in certain noun phrases serving an appositive or adverbial function, and in subject noun phrases not immediately preceded by a verb.

On the view that Welsh noun phrases are lenited by default, the lenition of the direct object in (13) requires no explanation; lenition is what is

[9] Thus, in Zwicky's analysis, the Trigger Constraint is satisfied by individual phrase structure rules, such as (18); but this is only possible because Zwicky represents phrase structure rules in the traditional manner rather than in the ID/LP format advocated by Gazdar, Klein, Pullum and Sag (1985). In the latter format, syntactic relations of immediate dominance and linear precedence are specified by distinct sets of rules; for example, the ID/LP version of rule (18) would consist of the immediate dominance rule in (i) and the linear precedence rule in (ii):

(i)

$$
\left.\begin{array}{cc}
\mathrm{VP} \rightarrow & \mathrm{V} \\
{[+\mathrm{FIN}]} & {\left[\begin{array}{c}
+\mathrm{FIN} \\
\text { LEN trigger }
\end{array}\right]}
\end{array} \quad, \quad \begin{array}{c}
\mathrm{NP} \\
+\mathrm{ACC} \\
+\mathrm{LEN}
\end{array}\right]
$$

(ii) $\mathrm{V}<\mathrm{NP}$

In this framework, the Trigger Constraint would clearly have to be viewed not as a restriction on individual rules, but rather as a restriction on rule pairings such as $\langle(i)$, (ii) $\rangle$. In what follows, I shall continue to follow Zwicky in assuming the traditional format for phrase structure rules. I have made this choice purely for expository reasons; that is, I think it should be possible to adapt analyses such as Zwicky's to an ID/LP format, but that the technical complications which this would entail would distract from the main issues at hand. 
expected, given the absence of a neighbouring mutation trigger. What does require an explanation is the absence of any mutation in the subject of a sentence such as (19), or in the object of an infinitive construction such as that in (14).

(19) Mae bleiddiau yn Rwysia. are wolves in Russia 'Wolves are in Russia.'

To account for the absence of mutation in these cases, Zwicky suggests that verbs impose the rule feature [-LEN] on an immediately following NP. On this analysis, it is the verb and its subject which have the status of trigger and target in (19); similarly, the nonfinite verb and its direct object stand in the trigger-target relation in (14). What is crucial here is that in both cases, the posited relation between trigger and target is in full conformity with the Trigger Constraint. ${ }^{10}$

\section{ZWICKY'S ACCOUNTS OF WELSH DIRECT OBJECT LENITION} APPLIED TO THE PROBLEM OF NON-LOCAL SPIRANTIZATION IN BRETON

Despite the apparent adequacy of Zwicky's solutions to the problem posed by lenited direct objects in Welsh, it does not seem to be possible to develop analogous solutions to the problem presented by non-local mutations in Breton, as will be shown in this section. Thus, unlike the Welsh phenomenon of direct object lenition, the non-local spirantizations in Breton expressions such as va holl zud 'all my people' present a genuine difficulty for the strong version of the Trigger Constraint.

\section{I. The discontinuous constituent analysis}

One way in which the apparently non-local spirantizations in (I0)-(12) might be accounted for is by an approach directly analogous to Zwicky's 'phantom VP' analysis of Welsh direct object lenition. On this approach, the non-local spirantization in a noun phrase such as $(20 \mathrm{~b})$ is brought into conformity with the Trigger Constraint by means of a prenominal adjective metarule.

[10] Since the appearance of Zwicky's paper, Harlow (to appear) has proposed a very different account of Welsh direct object lenition; he argues that the peculiarities of direct object lenition can be accounted for most simply under the assumption that noun phrases function as lenition triggers in Welsh. The relative merits of Harlow's and Zwicky's approaches are, of course, not at issue here; for my present purposes, I am most interested in the formal possibilities which these approaches raise for the analysis of non-local spirantizations in Breton. Because direct object lenition arises through the influence of a superficially adjacent trigger in Harlow's analysis, it is not clear that his account suggests any useful strategies for handling the Breton data. 
(20) (a) va zud
'my people'

(b) va holl zud

my all people

'all my people'

Thus, suppose that the noun phrases in (20) are admitted by the respective phrase structure rules in (2I) and (22). The trigger-target relation specified by rule (2I) is in full conformity with the Trigger Constraint; rule (22), on the other hand, admits non-local spirantizations, in apparent conflict with the Trigger Constraint. If (22) were, however, to derive from (2I) by means of a prenominal adjective metarule such as (23), then the trigger-target relation in (22) would be licensed by the acceptability of the corresponding relation in rule (21).

(21) NP $\rightarrow$ $\begin{array}{cc}\text { Det } & \mathbf{N} \\ {[\text { SPI trigger }]} & {[+\mathrm{SPI}]}\end{array}$

(22) $\mathrm{NP} \rightarrow$ Det Adj N [SPI trigger] [+SPI]

(23) Prenominal adjective metarule:

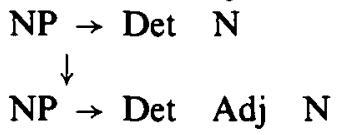

I shall call this approach to non-local spirantizations the DISCONTINUOUS CONSTITUENT ANALYSIS.

Whatever the merits of the 'phantom VP' analysis of Welsh direct object lenition, it is clear that the discontinuous constituent analysis of Breton spirantization cannot be maintained. To begin with, the prenominal adjective metarule at the core of this analysis is blatantly ad hoc; the very notion that [Det $\mathrm{N}$ ] may be a discontinuous constituent of a noun phrase of the form [Det Adj N] lacks any independent motivation in Breton. Moreover, if pursued to its logical conclusion, such an analysis would require structurally identical noun phrases to be admitted by the grammar in two very different ways.

To see this, recall first that it is only when the determiner is a spirantizer that the head noun undergoes a non-local mutation in a noun phrase of the form (24):

\section{(24) [Det holl $\mathrm{N}]$}

When the determiner is one which triggers any mutation other than spirantization ${ }^{11}$ (or is one which triggers no mutation at all), holl itself

[11] Recall from Section 2 that the determiner hor produces the defective spirantization of $k$ $\left(\rightarrow c^{\prime} h\right)$, as do the definite and indefinite articles in certain contexts; but because they do not produce the full range of spirantizations in Table $I$, they do not qualify as spirantizing determiners in the sense intended here. 


\section{NON-LOCAL SPIRANTIZATION IN BRETON}

triggers a (local) lenition of the following noun, as the examples in (25)-(27) show.

(25) (a) ho holl zaeroù 'all your tears' (holl lenites daeroù 'tears')

(b) ho taeroù 'your tears' (ho 'your' reinforces daeroù 'tears')

(26) (a) an holl di 'the whole house' (holl lenites $t i$ 'house') an ti 'the house' (an 'the' produces no mutation in $t i$ 'house (masc.)')

(27) (a) hon holl diegezh 'our whole family' (holl lenites tiegezh 'family')

(b) hon tiegezh 'our family' (hon 'our' produces no mutation in tiegezh 'family')

Recall, too, that the only adjective which may intervene between a spirantizing determiner and its target noun is holl; when any other adjective intervenes, the only possible mutations are local ones, with Adj as the only possible target for Det and the only possible trigger for $\mathrm{N}$, as (28) shows.

(28) (a) o zri grouadur 'their three children'

(o 'their' spirantizes $t r i$ 'three', which lenites ${ }^{12}$ krouadur 'child')

(b) he c'hozh kazeg 'her old mare'

(he 'her' spirantizes kozh 'old', which produces no mutation in kazeg 'mare')

Consider the consequences of these facts for the discontinuous constituent analysis, according to which noun phrases exhibiting non-local spirantizations can only be admitted by the phrase structure rule in (22). This rule, again, is induced by means of the prenominal adjective metarule, whose raison d'être is to license the trigger-target discontinuity in noun phrases of the form (29).

(29) [Det

$\left.\begin{array}{lll}{[\text { Det holl }} & \mathrm{N}\end{array}\right]$

On the other hand, noun phrases in which no non-local mutation is possible must never arise as an effect of the metarule; their prenominal adjectives must instead be directly introduced by means of basic phrase structure rules such as those in (30), which license only local mutations (i.e. the mutation of Adj by Det and of $\mathrm{N}$ by Adj), if any.

[12] Note that the numeral adjectives tri/leir 'three (masc./fem.)', pevar/peder 'four (masc./ fem.)', and nav 'nine' vary dialectally in their status as mutation triggers, serving either to spirantize or (as in (28a)) to lenite a following voiceless stop. See Hemon (1975a: $6 \mathrm{f}$.), Kervella (1947: 95 f.), and Trépos (n.d. [1968]: 48 f.). 


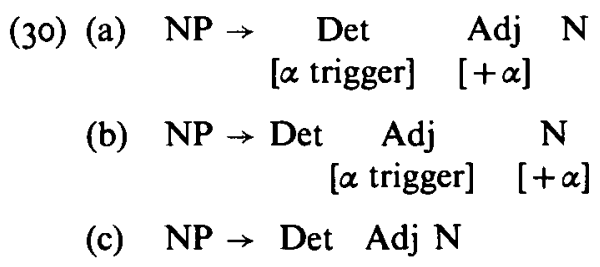

Thus, the discontinuous constituent analysis leads inevitably to the conclusion that noun phrases of the form (29) are admitted by the grammar in an entirely different way from all other noun phrases of the form [Det Adj $\mathrm{N}$. It is unclear how this bipartite analysis of Breton noun phrases can be taken seriously, especially in view of the complete absence of independent evidence for such an analysis.

\subsection{The default spirantization analysis}

We will now show that the default lenition analysis has no convincing analogue capable of accounting for the non-local spirantizations observed within Breton noun phrases.

Suppose that as a basic principle of Breton grammar, all nouns were spirantized by default, undergoing other mutations (or no mutation at all) only through the influence of an adjacent trigger. If this were the case, then the spirantization of the head of a noun phrase such as (20b) va holl zud would not have to be viewed as a non-local mutation; on the contrary, this spirantization could seemingly simply be regarded as arising by default, and not as the effect of any trigger's influence.

The insuperable difficulties with such an analysis should be immediately obvious, however. Recall, to begin with, that holl itself ordinarily lenites a following noun, as in (25a)-(27a); according to the assumptions of the default spirantization analysis, however, this should cause holl to override the default spirantization of tud in $(20 \mathrm{~b})$, producing the ungrammatical result in (31).

(3I) *va holl dud

Moreover, the very notion that spirantization is a default process for Breton nouns is highly improbable: unlike lenition in Welsh, Breton spirantization is a highly restricted phenomenon, triggered by fewer than ten expressions (namely $v a$ 'my', he 'her', $o$ 'their', the first person singular enclitic - $m$, and in some dialects, tri/teir 'three (masc./fem.)', pevar/peder 'four (masc./ fem.)', and nav 'nine'). This is in sharp contrast to lenition, which appears in a wide range of contexts, in Breton as in Welsh. Moreover, the appearance of Breton spirantization, unlike that of Welsh lenition, is always associated with the concurrent appearance of a triggering expression. In short, Breton spirantization does not have the character of a default phenomenon. The 
range of contexts where it appears is not a long and heterogeneous list of environments of the sort most easily characterized as 'elsewhere', but is instead a highly circumscribed list comprising between four and nine individual environments. Thus, despite the success of Zwicky's proposal of default lenition as a way of reconciling Welsh direct object lenition with the Trigger Constraint, an analogous proposal of default spirantization for Breton would plainly be inadequate as a way of bringing non-local spirantizations into conformity with the Trigger Constraint.

\section{TWO ALTERNATIVE APPROACHES TO RECONCILING BRETON Non-local mutations with the Trigger Constraint}

Although the two analyses discussed in Section 4 provide no credible means of bringing Breton spirantizations into conformity with the Trigger Constraint, other analyses are certainly imaginable. In this section, two additional approaches to the problem posed by Breton spirantizations are scrutinized; as will be seen, however, neither is any more satisfactory than the two approaches rejected above.

\subsection{The head feature analysis}

Given the evidence presented so far, a very different solution to the problem of non-local mutations in Breton might still appear to be possible; this approach, which I shall call the HEAD FEATURE ANALYSIS, is based on the hypothesis that the mutation features which triggers impose on their targets function non-standardly as head features in Breton.

A critical assumption in this analysis is that Breton noun phrases of the form [Det holl $\mathrm{N}]$ have the structure in (32).

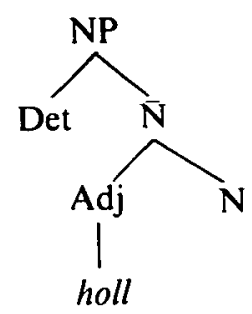

Given this assumption, the Trigger Constraint predicts that $\mathrm{N}$ should be the only possible target for the lenition triggered by holl in (32). If the determiner in (32) is a mutation trigger, however, it could in principle have either $\bar{N}$ or Adj as its target. Suppose that $\overline{\mathbf{N}}$ is the target of Det, and that the mutation feature imposed on $\overline{\mathrm{N}}$ by Det is passed to $\mathrm{N}$ by the Head Feature Convention (cf. Gazdar, Klein, Pullum \& Sag, 1985: $94 \mathrm{ff}$.). Under these circumstances, $\mathrm{N}$ ends up with two possibly conflicting mutation features - the feature [ $+\mathrm{LEN}]$ triggered by holl and whatever feature is triggered by Det. 
Languages do, of course, provide means for resolving such cases of feature conflict; what is significant here is that most of the data discussed so far can be made to conform to the Trigger Constraint if the following feature resolution principle is adopted.

(33) If $\mathrm{N}$ bears two conflicting mutation features, it retains whichever one of these features is higher in the following hierarchy: $[+\mathrm{SPI}]>[+\mathrm{LEN}]>[+\mathrm{REI}]$.

According to this analysis, the head noun tud 'people' in (34) receives two mutation features: the first, [+LEN], is directly imposed by the adjacent lenition trigger holl; the second, [+SPI], is imposed by $v a$ 'my' onto $\overline{\mathrm{N}}$, from which it is transmitted to $t u d$ by the Head Feature Convention. (33) resolves the resulting feature conflict in favour of $[+\mathrm{SPI}]$.

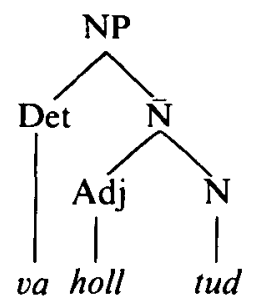

Consequently, the resulting expression va holl zud appears to be one in which the determiner has triggered a non-local spirantization. Given the assumptions of the head feature analysis, however, this mutation is entirely local, since the determiner c-commands and is adjacent to its target, $\overline{\mathbf{N}}$; the local nature of this trigger-target relation is simply obscured by the manner in which the Head Feature Convention and principle (33) interact.

Note that principle (33) predicts that because holl is a lenition trigger, its effects on a following $\mathrm{N}$ should only be able to be overriden by a determiner which triggers spirantization. This prediction is borne out: the only determiners capable of mutating a noun despite the intervention of holl are the spirantizing determiners, $v a$ 'my', he 'her', and $o$ 'their'.

This analysis is very appealing, but further data demonstrate that it is wrong ; in particular, there is unequivocal evidence that mutation features are not transmitted by the Head Feature Convention. This is clearly demonstrated by noun phrases of the form [Det Adj $N$ ] in which the determiner triggers a mutation in the adjective rather than in the noun; the examples in (35)-(38) illustrate. (Cf. also (28).)

(35) e goshañ breur 'his oldest brother'

( $e$ 'his' lenites koshañ 'oldest' but not breur 'brother'; cf. e vreur 'his brother', in which $e$ lenites breur)

(36) ho kwasañ devezh 'your worst day'

(ho 'your' reinforces gwasañ 'worst' but not devezh 'day'; cf. ho tevezh 'your day', in which ho reinforces devezh) 
(37) ar c'hentañ kentel 'the first lesson'

( $a r$ 'the' produces the defective spirantization $k \rightarrow c$ ' $h$ in kentan 'first' but does not affect kentel 'lesson (fem.)' cf. ar gentel 'the lesson', in which ar lenites kentel)

(38) ur c'hozh kazeg 'an old mare'

( $u r$ ' $a$ ' produces the defective spirantization $k \rightarrow c$ ' $h$ in $k o z h$ 'old' but does not âffect kazeg 'mare (fem.)'; cf. ur gazeg 'a mare', in which ur lenites kazeg)

(Note that the articles $a r$ and $u r$ trigger a highly defective mutation, whose sole effect is the conversion of an initial $k$ to $c^{\prime} h$, when their target is an adjective, as in (37) and (38). ${ }^{13}$ )

It is clear that in each of $(35)-(38)$, the mutation feature imposed by the determiner is not passed from $\overline{\mathbf{N}}$ to $\mathrm{N}$ in accordance with the Head Feature Convention; rather, it appears that this feature is imposed directly onto the intervening adjective. But if this is so, then the mutation of the noun in an expression such as va holl zud cannot be viewed as a local mutation of $\bar{N}$ whose apparently non-local status is an effect of the Head Feature Convention and principle (33).

One might suppose that the feature resolution principle (33) could be modified so as to predict the absence of any mutation in the head nouns of (35)-(38). In particular, one might introduce a rule feature [-MUT], whose effect would be to prevent an expression so marked from undergoing any mutation; using this new feature, one might then revise principle (33) as follows:

$\left(33^{\prime}\right)$ If $\mathrm{N}$ bears two conflicting mutation features, it retains whichever one of these features is higher in the following hierarchy: $[-\mathrm{MUT}]>[+\mathrm{SPI}]>[+\mathrm{LEN}]>[+\mathrm{REI}]$

Now, none of the adjectives in (35)-(38) is a mutation trigger - that is, each would impose the feature [-MUT] on the following noun. Thus, by virtue of principle $\left(33^{\prime}\right)$, this feature would override whatever feature were imposed

[13] Actually, there is dialect variation in the ways in which articles mutate prenominal adjectives; cf. Hemon (1975a: II), Kervella (1947: 88, 97), Le Gléau (1973: 55-56, 66), Trépos (n.d. [1968]: 118 f.). In some varieties of spoken Breton, the articles trigger the lenition of a prenominal adjective if the following noun is itself one which would undergo lenition when immediately preceded by an article: thus, because maouez 'woman' is a feminine singular noun, gwellañ 'best' is lenited in (i); but because paotr 'boy' is masculine singular, gwellañ remains unlenited in (ii).

(i) ar wellañ maouez 'the best woman'

(ii) ar gwellañ paotr 'the best boy'

What is important here is that even in the dialects which treat prenominal adjectives as in (i) and (ii), the noun following such an adjective is unaffected by the preceding determiner; note, for example, that maouez remains unlenited in (i) (cf. ar vaouez 'the woman'). 
on $\bar{N}$ (and hence on $\mathbf{N}$ ) by the determiner. For this reason, (33') would correctly account both for the spirantization of the head noun in va holl zud and for the non-mutation of the head nouns in (35)-(38). Leaving aside the issue of how the adjectives in (35)-(38) become mutated, one might therefore suppose that $\left(33^{\prime}\right)$ could provide a secure basis for repairing the head feature analysis.

It turns out, however, that the revised principle makes incorrect predictions about certain sorts of examples. Specifically, (33') predicts that if a head noun is preceded by a determiner which triggers no mutation and by an adjective which does trigger some mutation, then the head noun should not undergo any sort of mutation, that the determiner's influence should override that of the adjective in such cases. Counterexamples to this prediction are nevertheless commonplace; a single instance will be discussed here. Recall that the definite article never triggers any sort of mutation in a noun which is masculine, is non-human in reference, and begins with a consonant other than $k$. Thus, the masculine noun marc' $h$ 'horse' is never mutated by the definite article, as the pair of examples in (39) shows.
(39)
(a) ar marc'h 'the horse'
(b) ar mirc'hed 'the horses'

The numeral adjective daou/div 'two (masc./fem.)', however, regularly functions as a lenition trigger:

(40) daou varc'h 'two horses'

Thus, if the definite article and the numeral daou are viewed as imposing the respective rule features [-MUT] and [ $+\mathrm{LEN}]$ when they appear in a phrase headed by marc' $h$, then principle (33') unequivocally predicts that marc' $h$ should remain unmutated in that phrase; but this is incorrect, as (4I) shows.

(4I) (a) *an daou marc'h (marc' $h$ 'horse' remains unmutated)

(b) an daou varc'h 'the two horses' (marc' $h$ is lenited)

Consequently, principle $\left(33^{\prime}\right)$ is untenable. (The same conclusion can be established with similar examples involving the numeral adjectives tri/teir 'three (masc./fem.)', pevar/peder 'four (masc./fem.)', and nav 'nine'; such examples are, however, complicated by the fact that the mutations which these numerals trigger vary dialectally - see footnote I2.)

\subsection{The cliticization analysis}

In view of the data presented up to this point, one final sort of solution might yet be thought capable of reconciling the Breton data and the Trigger Constraint with a minimum of special assumptions; this last approach will be called the CLITICIZATION ANALYSIS. 
In the head feature analysis, it was assumed that a noun phrase of the form [Det holl $\mathrm{N}]$ has the structure in (32), repeated here:

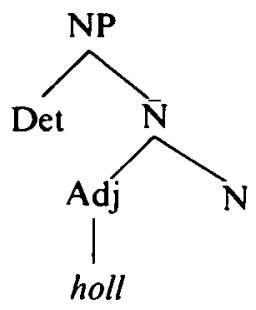

Suppose, however, that a NP of this sort instead has the structure in (42), in which holl is structurally enclitic to the preceding determiner.

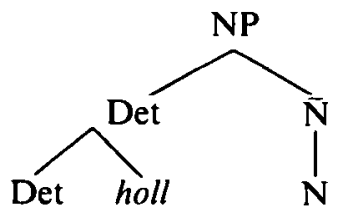

Now, consider the following hypothesis:

(43) Hypothesis:

A complex structure of the form [head clitic] triggers the same mutation as its head triggers in the absence of the clitic.

According to this hypothesis, the complex determiner [Det holl] in (42) should trigger the same mutation as Det does when it appears independently. If valid, this hypothesis would allow the apparently non-local spirantization of $t u d$ by $v a$ in $v a$ holl zud to be viewed as the local spirantization of $t u d$ by the complex determiner [ $\mathrm{va}$ holl]. In combination with structure (42), hypothesis (43) appears to provide a natural account of the data at issue, and one which reconciles such expressions with the Trigger Constraint. Unfortunately, this cliticization analysis has a number of defects.

The first defect is, of course, that there are many 'Det holl' sequences which do not trigger the same mutation as their determiner triggers in the absence of holl. In Section 4. I above, it was pointed out that only spirantizing determiners may produce a mutation in a following noun despite the intervening presence of holl; thus, in example (44) (=(25a)), ho 'your (pl.)' is a reinforcing determiner, so that it is the intervening adjective holl rather than the determiner which triggers the mutation of the target noun.

(44) ho holl zaeroù 'all your tears' (holl lenites daeroù 'tears')

Clearly, if hypothesis (43) is to be maintained, noun phrases of the form (24) must be assigned two distinct constituent structures: those with spirantizing determiners must be assigned the structure in (42) (in which holl is enclitic) 
while those with other kinds of determiners must be assigned a structure in which holl is not enclitic, as in (32).

\section{(24) [Det holl $\mathrm{N}]$}

That is, in order to maintain hypothesis (43), holl must be viewed as cliticizing onto spirantizing determiners, but not onto determiners of other sorts.

This proposed structural difference between noun phrases of the form (24) is, needless to say, devoid of independent motivation. More importantly, however, hypothesis (43) appears to be decisively disconfirmed by independent evidence from Breton. Central to this evidence is the fact that under particular circumstances, the determiner in a prepositional phrase such as (45) must cliticize onto the preceding preposition, as in (46).
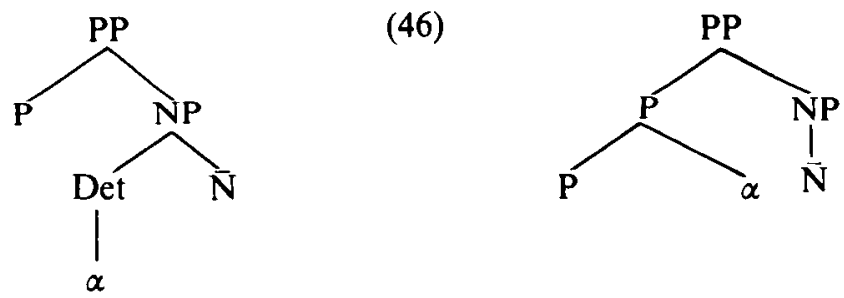

Specifically, this kind of cliticization is observed when (a) the preposition is either $d a$ 'to' or $e$ 'in', and (b) the determiner is $v a$ 'my' or $d a$ 'thy'. The cliticized forms of these possessive determiners are easily identified, for they each consist of a single consonant: $v a$ reduces to ' $m$, and $d a$ to ' $z$.

Now, the preposition $d a$ lenites its object, as (47) shows:

(47) da Gemper 'to Quimper' (da 'to' lenites Kemper 'Quimper')

Accordingly, hypothesis (43) would lead one to expect that the host-clitic combinations $d a^{\prime} m$ 'to-my' and $d a^{\prime} z$ 'to-thy' would exhibit the leniting properties of their head, the preposition da. This prediction is, however, strikingly disconfirmed in both cases: the combination da'm triggers a spirantization and the combination $d a^{\prime} z$ triggers a reinforcement, as (48) and (49) show. ${ }^{14}$

(48) da'm zad 'to my father' (da' $m$ 'to-my' spirantizes $t a d$ 'father') (49) da'z preur 'to thy brother' ( $d a^{\prime} z$ 'to-thy' reinforces breur 'brother')

This evidence strongly suggests that hypothesis (43) is incorrect.

To summarize, it has been shown in this section that the spirantization observed in a Breton noun phrase such as va holl zud cannot be convincingly

[14] Thus, da'm 'to-my', like nonclitic va 'my', is a spirantizer. Quite unexpectedly, however, $d a$ ' $z$ 'to-thy' is a reinforcer, unlike the leniting nonclitic $d a$ 'thy'. 
analysed as a local spirantization of $\overline{\mathrm{N}}$ by Det, nor as a local spirantization of $\mathrm{N}$ by a complex determiner of the form [Det holl].

\section{An alternative view of the Trigger Constraint}

In view of the foregoing arguments, consider now the status of the Trigger Constraint. To all appearances, Zwicky's statement of this constraint in (I) is untenable; the Breton data discussed here certainly cannot be reconciled with it by ordinary means. It is clear, however, that Zwicky's version of the Trigger Constraint does embody the unmarked case in language: morphophonemic systems adhering to this version are commonplace, while exceptional systems such as the one discussed here are quite rare. ${ }^{15}$

The Breton mutation system itself just barely qualifies as an exception to (I); indeed, this system is in complete conformity to (I) except as regards noun phrases of the sort schematized in (50), in which the determiner produces a mutation of the non-adjacent noun.

\section{(50) [Det holl $\mathrm{N}$ ], where Det is a [SPI trigger]}

Moreover, non-local spirantizations are only found in noun phrases of this sort in certain dialects of Breton: according to Hemon (1975b: 22), for example, the spirantizing determiners never produce non-local mutations in the standard literary dialect, even when they appear in the context in (50) ${ }^{16}$

[I 5] As Jim McCloskey has pointed out to me, there are cases of non-local mutation in Modern Irish: in configurations of the form [ Poss $d h a$ ' $]$ (where Poss is a possessive proclitic and $d h a$ is the numeral 'two', ordinarily a lenition trigger), $\mathrm{N}$ is not lenited by dha, but is instead subject to the mutation-triggering properties (or lack thereof) of Poss, as in examples (i)-(iii).

(i) a dhá bhád 'his two boats' ( $a$ 'his' lenites bád 'boat')

(ii) a dhá bád 'her two boats' ( $a$ 'her', a non-trigger, produces no mutation in bad)

(iii) a dhá mbad 'their two boats' ( $a$ 'their' nasalizes bad)

Cf. De Bhaldraithe, 1953: 268, note I.

A different sort of non-local mutation appears in Old Irish: Hamp (I951 : 238) notes that 'certain conjunctions nasalize not the form immediately following, but the next-but-one, if it is a compound verb...' As an example, he cites the subordinating conjunction in tain 'when', which locally nasalizes a following simple verb (e.g. in tain mberes 'when he carries') but produces an apparently non-local nasalization if the following verb is compound (e.g. in tain do-mbeir 'when he gives').

Finally, Jerry Sadock has pointed out that what might otherwise appear to be an utterly idiosyncratic quirk of spoken English bears an unexpected similarity to the phenomenon of non-local spirantization in Breton. If the English indefinite article $a$ were regarded as a mutation trigger which 'prenasalized' a following vowel-initial target, then the difference between an apple and a dog could be (whimsically) explained as the effect of an initial mutation process. Startingly, however, there is a named element which can intervene between the indefinite article and its 'target', and this intervener is none other than the adjective whole ('holl'), as in a whole nother thing.

[16] Certain grammars and dictionaries consulted during the preparation of this study contain examples which likewise show that non-local spirantizations are not universal in Breton; in each of the following examples of the form [Det holl $\mathrm{N}$ ], the head noun is lenited by holl 
and as was mentioned above, this context is simply absent from certain other dialects, which altogether lack the adjective holl.

It seems, in addition, that non-local spirantization is highly variable and unstable in those dialects in which it appears. In my discussion here, I have focused on the dialects described by Kervella (1947: 97) and Trépos (n.d.[1968): 46) as a kind of norm; in these dialects, spirantizing determiners uniformly produce a non-local mutation in the noun phrase configuration in (50). There are, however, at least five ways in which other dialects diverge from this 'normal' pattern of non-local spirantization. In the dialect described by Moal ( $1890: 63 \mathrm{f}$.), a spirantizing determiner only produces a non-local mutation in the configuration (50) when the noun to be mutated is feminine or plural. In the variety of the Trégorrois dialect described by Hingant (I 868: 47), only the spirantizing determiner he 'her' effects a nonlocal mutation in the configuration (50), and then only if the noun to be mutated begins with $p$; in other words, the non-local mutation is, in this dialect, a defective spirantization produced by only a single trigger and affecting only a single consonant. Malmanche (1907:63) describes a variety of the Léon dialect which appears to differ minimally from that of Hingant; in this dialect, $p$ is again the only consonant subject to non-local spirantization, but in this case, the triggering determiner may be either $v a$ 'my' or he 'her'. ${ }^{17}$ Le Gléau (1973: 54) mentions that in some varieties of the language, holl is not the only element that can possibly intervene between a spirantizing determiner and its nominal target: gwir 'true' and eil 'second' are likewise possible interveners in these varieties. (Cf. also Kervella, 1947: 97.) Finally, Le Roux ( $1896: 31$ ), describing the Pleubian dialect of Trégorrois, notes that two mutation patterns are possible in the configuration [Det daou $\mathrm{N}$ ] (where Det is a spirantization trigger and daou is the numeral 'two'): (i) Det may non-locally spirantize $\mathbf{N}$ when the intended interpretation is one in which the possessor designated by the determiner is emphasized e.g. he daou fark 'HER two fields' (park 'field'); but (ii) daou, a lenition trigger, may locally mutate $\mathrm{N}$ for an unemphatic interpretation - e.g. he daou bark 'her two fields'. ${ }^{18}$ Thus, there are at least six different patterns of non-

rather than being spirantized by the preceding determiner. (Spellings are left as in the original sources, some of which employ non-standard orthographies.)

Hemon (1975 b: 22):

va oll bec'hejou 'all my sins',

ho holl dud 'all their people';

Le Clerc (19I I : 22):

Troude (1842: 563$)$ :

Vallée (1926: 103): ma oll vado 'all my goods'; va holl zizoan 'my whole consolation'; va holl vadou 'all my goods'.

[17] In the dialect described by Malmanche, holl produces a local lenition of $\mathrm{N}$ in the configurations ' $v a$ holl $\mathrm{N}$ ' and 'he holl $\mathrm{N}$ ' in those cases in which $\mathrm{N}$ begins with a consonant other than $p$. It is unclear from Hingant's discussion whether this is true of his dialect as well.

[18] He daou bark 'her two fields' is phonetically indistinguishable from $e$ daou bark 'his two fields'; thus, as Le Roux observes, it is not at all surprising that the unambiguous alternant he daou fark should be exploited as a way of emphasizing the possessor (cf. footnote 8). 
local spirantization found in different varieties of spoken Breton, while still other varieties of the language lack any such phenomenon at all. This suggests that non-local mutations are marked and unstable; certainly they are strikingly less regular in their occurrence from one dialect to another than most of the uncontroversial, local mutations associated with Breton.

\section{TWO SOLUTIONS TO THE PROBLEM OF NON-LOCAL MUTATIONS}

To summarize, Zwicky's version (I) of the Trigger Constraint might be construed as characterizing unmarked morphophonemic systems. Granted that exceptions to (I) are rare and unstable, the question now becomes: How can these exceptions be accounted for? What, exactly, is the nature of the marked option exploited by a morphophonemic system which exhibits nonlocal mutations? In this section, I shall briefly discuss two possibilities.

\subsection{The intervention analysis}

The first solution is to weaken the Trigger Constraint so that it allows for non-local mutations as a marked option in morphophonemic systems. Note that that part of the Trigger Constraint which requires that a trigger c-command its target is not falsified by any of the cases discussed here; thus, what must be weakened is the requirement that a trigger be adjacent to its target. One need not resort to outright abandonment of this restriction, however, since there are apparently very severe limits on what can possibly intervene between a trigger and its target: in particular, the data discussed here would be fully consistent with a requirement that the intervening material be a NAMED ELEMENT, since the only possible intervener in the cases of non-local mutation discussed here is the adjective holl (and possibly also the adjectives gwir, eil, and daou, depending on the dialect). ${ }^{19}$ (5I) might therefore be proposed as a sufficiently weakened version of the Trigger Constraint.

(51) Revised Trigger Constraint:

The trigger determining a rule feature for a morphophonemic rule

(i) must c-command the target word and

(ii) may be separated from the target word by at most one named element, adjacency being the default option.

(Note that $e$ "his' does not produce a lenition in daou 'two' in $e$ daou bark because $d$ always resists lenition in Trégorrois.)

Examples cited from Le Roux (1896) have been rendered into standard orthography.

[19] The notion that only named elements may intervene in cases of non-local mutation is confirmed by the Modern Irish data cited in footnote 15. Whether it is likewise confirmed by the Old Irish data cited in that footnote is less clear : in the Old Irish case, the expressions which may intervene in instances of non-local mutation all fall into a coherent category, namely the category of prepositional prefixes. Whether ALL such prefixes are possible interveners remains unclear, however. Moreover, the class of prepositional prefixes is closed, and has a vanishingly small membership. 
This revision of the Trigger Constraint is the basis for what I shall call the INTER VENTION ANALYSIS of non-local mutations. In this analysis, it is assumed that the phrase structure rules of Breton are not responsible for the distribution of morphophonemic rule features; rather, this is taken to be the responsibility of an interpretive component operating on the tree structures admitted by the syntax. A universal default principle of this interpretive component would be (52):

(52) A default principle of universal grammar:

In the configuration [ $\left.\begin{array}{lll}A & B\end{array}\right]$, [ $\alpha$ trigger]

A imposes the morphophonemic rule feature $[+\alpha]$.

In the default cases covered by (52), the target expression on which a particular rule feature is imposed would be uniquely identified by the revised Trigger Constraint $(51)$ as that word which is c-commanded by the trigger and which is adjacent to it.

As a default principle, however, (52) could be overriden by languagespecific rules for the distribution of morphophonemic rule features. In particular, non-local spirantizations might appear in Breton as a consequence of the language-specific rule in (53).

(53) A principle of Breton grammar:

In the configuration [ Det [ holl $\mathrm{N}]$ ],

[SPI trigger]

Det imposes the morphophonemic rule feature $[+\mathrm{SPI}]$ on $\mathrm{N}$.

Though the trigger-target relation in (53) is not one of adjacency, it would still be licensed by the revised Trigger Constraint since the intervening expression is a named element. And because rule (53) would apply in a proper subset of the configurations in which (52) might apply, the application of (53) would correctly precede and exclude that of (52), in accordance with the general principle of disjunctive rule application discussed by Kiparsky (1973).

\subsection{The transfer analysis}

The intervention analysis is, I think, reasonably satisfying, but it is important to recognize that it is not the only imaginable means of accounting for nonlocal mutations as a marked phenomenon in morphophonemic systems. A very different approach exists which actually allows the Trigger Constraint to be maintained in its original, stronger form; this alternative analysis diverges radically from ordinary approaches to the description of mutation systems, and I want to thank Steve Harlow for encouraging me to consider it seriously.

According to this alternative solution, the spirantizing determiner in the 
configuration (50) is not what triggers the spirantization of the head noun, or, at least, not directly. Instead, it is assumed that the spirantizing properties of the determiner are, as it were, 'transferred' to holl, whose own leniting properties are thereby supplanted; once this transfer has taken place, holl produces a local spirantization of the adjacent head noun. This approach which I shall call the TRANSFER ANALYSIS - has the advantage of being consistent with Zwicky's original, simpler version of the Trigger Constraint. However, unless the rules which transfer mutation-triggering properties from one word to another are sufficiently constrained, the transfer analysis actually runs the risk of reducing the Trigger Constraint to vacuity.

The problem, of course, is that if mutation-triggering properties could be transferred without restriction from one expression to another, then one could, in effect, regard ANY structural relation between a mutation trigger and its target as conforming to the Trigger Constraint; even if a trigger were structurally very distant from its target, one could simply postulate a rule transferring the mutation-inducing properties from the remote position occupied by the trigger to a position c-commanding and adjacent to the target expression. To avoid this problem, the proposed transfer rules would have to be highly restricted in their capabilities. Seemingly, the mutationtriggering property of some expression $\alpha$ should only be able to be transferred to an adjacent named element c-commanded by $\alpha$; and once a property has been so transferred, it should not be available for further transfer. These restrictions are summarized in (54).

(54) Constraints on transfer rules:

If a rule $\mathrm{r}$ transfers a mutation-triggering property $\mathrm{M}$ from $\alpha$ to $\beta$, then

(i) $\alpha$ must c-command $\beta$;

(ii) $\alpha$ must be adjacent to $\beta$;

(iii) $\beta$ must be a named element in $\mathrm{r}$; and

(iv) $M$ cannot be further transferred from $\beta$.

If it is assumed that transfer rules are so constrained, then the normal pattern of non-local spirantization in Breton might be accounted for by means of the transfer rule (55).

(55) A principle of Breton grammar:

In the configuration [ Det [ holl ... ] ],

[SPI trigger]

the triggering property [SPI trigger] is transferred from Det to holl (where it supplants the triggering property [LEN trigger]).

By converting structures such as (56) to the form (57), rule (55) would bring their trigger-target relations into full conformity with the strong version of the Trigger Constraint proposed by Zwicky. 


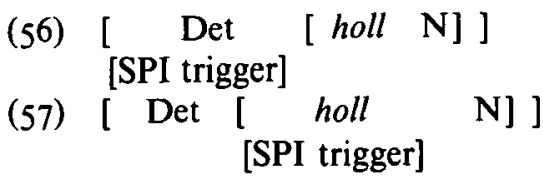

Structures such as (57) might then be subject to an interpretive principle essentially like (52) for the distribution of their mutation features.

\section{Conclusion}

Despite their obvious differences, the intervention analysis and the transfer analysis afford two credible accounts of the marked option exploited by morphophonemic systems exhibiting non-local mutations. The intervention analysis permits the option of weakening the adjacency requirement to which triggers and targets are ordinarily subject to the extent of allowing a named element to intervene between a trigger and its target. According to the transfer analysis, on the other hand, the marked option signalled by the appearance of non-local mutations is the option of employing rules of an unprecedented sort, whose effect is to transfer the mutation-triggering property of a given expression to an adjacent named element. I do not know of any empirical grounds for choosing between these two analyses; the issue is probably one which will have to be settled by purely metatheoretical criteria. Because rules which transfer mutation-triggering properties are without clear independent motivation, the transfer analysis might, for example, be rejected in the interests of maintaining a parsimonious inventory of possible rule-types. On the other hand, the revised Trigger Constraint might, for instance, be viewed as an ugly complication of a constraint whose original, simpler version is decisively favoured by some particular standards of simplicity or naturalness.

One objection, however, can clearly be levelled at both analyses, namely that in their present forms, they are both overly stipulative. Consider, for example, the constraints on transfer rules listed in (54): ideally, these should follow as theorems from more fundamental principles. To this end, one might propose to treat the transfer of a mutation-triggering property (such as [SPI trigger]) as the same type of operation as the imposition of a morphophonemic rule feature (such as [ $+\mathrm{SPI}]$ ) by a trigger onto its target; if this were assumed, then clauses (i) and (ii) of (54) would follow as a direct consequence of the Trigger Constraint (in its original form ( $\mathrm{I})$ ).

The line of reasoning seems promising; it would not, however, provide any explanation for the residual clauses (iii) and (iv) in (54). Moreover, assimilating clauses (i) and (ii) of (54) to the Trigger Constraint would not appreciably diminish the stipulative nature of the transfer analysis, for the Trigger Constraint is itself baldly stipulative, both in its original form and in its revised form $(5 \mathrm{I})$. Thus, whether the intervention analysis or the transfer 
analysis is ultimately favoured, some sort of account must be given of those basic grammatical principles entailing the existence of the Trigger Constraint.

\author{
Author's address: University of Kentucky, \\ Lexington, \\ Kentucky 40506, \\ USA.
}

\title{
REFERENCES
}

Awbery, G. M. (1976). The syntax of Welsh: A transformational study of the passive. Cambridge: Cambridge University Press.

De Bhaldraithe, T. (1953). Gaeilge chois fhairrge: An deilbhiocht. Dublin: Institiúid Árd-Léinn Bhaile Átha Cliath.

Ernault, E. (1897). Petite grammaire bretonne. Saint-Brieuc: Prud'homme.

Ernault, E. (1984). Geriadurig brezhoneg-galleg. Brest: Brud Nevez.

Gazdar, G., Klein, E., Pullum, G. \& Sag, I. (1985). Generalized phrase structure grammar. Cambridge, Ma: Harvard University Press.

Guillevic, A. \& Le Goff, P. (1942). Grammaire bretonne du dialecte de Vannes. 4th ed. Vannes: Lafolye et J. de Lamarzelle.

Guillome, J. (1836). Grammaire française-bretonne. Vannes: J. M. Galles.

Hamp, E. (I95I). Morphophonemes of the Keltic mutations. Lg 27. 230-247.

Hardie, D. W. F. (1948). A handbook of modern Breton (Armorican). Cardiff: University of Wales Press.

Harlow, S. (to appear). The syntax of Welsh soft mutation. Natural Language and Linguistic Theory 7.

Hemon, R. (1975a). Grammaire bretonne. 8th ed. Brest: Al Liamm.

Hemon, R. (1975 b). A historical morphology and syntax of Breton. Dublin: The Dublin Institute for Advanced Studies.

Hemon, R. (1978). Nouveau dictionnaire breton-français. 6th ed., revised and expanded. Brest: Al Liamm.

Hingant, J. (1968). Éléments de la grammaire bretonne. Tréguier: Le Flem.

Jackson, K. H. (1967). A historical phonology of Breton. Dublin: The Dublin Institute for Advanced Studies.

Kervella, F. (1947). Yezhadur bras ar brezhoneg. 1976 reprint. Brest: Al Liamm.

Kiparsky, P. (1973). 'Elsewhere' in phonology. In Anderson, S. R. \& Kiparsky, P. (eds), A Festschrift for Morris Halle. New York: Holt, Rinehart and Winston. 93-106.

Le Clerc, L. (1911). Grammaire bretonne du dialecte de Tréguier. Saint-Brieuc: Prud'homme.

Le Fèvre, G. (1818). Grammaire celto-bretonne. Morlaix: Guilmer.

Le Gléau, R. (1973). Syntaxe de breton moderne (1710-1972). La Baule: Éditions La Baule.

Le Gonidec, J. (1838). Grammaire celto-bretonne. Paris: Delloye.

Le Roux, P. (1896). Mutations et assimilations de consonnes dans le dialecte armoricain de Pleubian. Annales de Bretagne 12. 3-3I.

Malmanche, T. (1907). Le mémento du bretonnant. Paris: Beauchesne.

Moal, J. (1890). Supplément lexico-grammatical au dictionnaire français-breton du colonel $A$. Troude. Landerneau: Desmoulins.

Normant, J.-M. (1902). Lexique breton-français. Quimper: Kerangal.

Société armoricaine du Breuriez ar Feiz. (1847). Nouvelle grammaire bretonne, d'après la méthode de Le Gonidec, suivie d'une prosodie. Saint-Brieuc: Prud'homme.

Sommerfelt, A. (1920). Le breton parlé à Saint-Pol-de-Léon. Rennes: Imprimeries Réunies.

Ternes, E. (1970). Grammaire structurale du breton de l'ille de Groix. Heidelberg: Carl Winter Universitätsverlag.

Treasure, J. P. (1903). An introduction to Breton grammar. Carmarthen: Spurrell and Son.

Trépos, P. (n.d. [1968]). Grammaire bretonne. 1980 reprint. Rennes: Ouest France.

Troude, A. E. (1842). Dictionaire français et celto-breton. Brest: Lefournier.

Vallée, F. (1926). La langue bretonne en 40 leçons. 7 th ed. Saint-Brieuc: Prud'homme.

Willis, P. (1982). The initial consonant mutations in the Brythonic Celtic languages. Unpublished CUNY doctoral dissertation.

Zwicky, A. M. (1984). Welsh soft mutation and the case of object NPs. CLS 20. 387-402. 